\title{
System and Policy in the Planning of Higher Education in Mexico
}

\author{
Gonzalo Varela-Petito \\ Department of Politics and Culture, Xochimilco Campus, Metropolitan Autonomous University, \\ Mexico City, Mexico \\ Email: vapg7469@correo.xoc.uam.mx
}

Received June $24^{\text {th }}$, 2012; revised July $27^{\text {th }}$, 2012; accepted August $11^{\text {th }}$, 2012

\begin{abstract}
In higher education in Mexico, the tension between institutional practice and the directives of government authority produces a scenario of uncertainty. In recent decades the government has used planning mechanisms in an attempt to induce a more solid direction all round. Such a policy tries to assert itself in generic criteria such as the opening of opportunities by increasing student enrollment numbers and the radius of social recruitment. It does not relinquish the maxim of educational achievement and quality of service. Nevertheless, given the interinstitutional complexity of the system, it is hard to ensure that these would bring about significant corrections in the short term. The crux of the matter lies in the resolution of the ties between the government and the Higher Education Institutions (HEIs), indeed, between centralization and autonomy. One escape route from this tension has been the parallel growth of the private higher education sub-system, but in relation to the public sector the approach of official policy has been to advance evaluations as a means of information and control.
\end{abstract}

Keywords: Mexico; Higher Education System; Higher Education Planning; Evaluation Policy

\section{Introduction}

Since the great student strike of 1968, public policy in Mexico began to pay closer attention to higher education. Previously, the Mexican government had opted to stay clear of the issues regarding university; however, as it now faced conflict stemming from an explosive rise in enrollment which itself created unsustainable pedagogical problems, educational authorities began to take the initiative. An attempt was made to bring mechanisms into the national environment for the development of higher education that had already been proven in other countries (Coombs, 1967). The chief idea here was a planning strategy that would be implanted more or less homogeneously within the various Higher Education Institutions (HEIs), most emphatically in the public universities, which, to this day, include the majority of students enrolled in higher education.

The attempt encountered two obstacles: the extreme heterogeneity and autonomy of the HEIs, and the excessive political pragmatism of government officials. Different impulses can be distinguished in this regard. The first of these, in the first half of the seventies, brought with it marked changes in educational policy, typically in the relatively haphazard application of an array of planning measures. A second one, running approximately from 1978 to 1986, represents a stage in which a greater unity and homogeneity was sought, overall, for higher education. A third period began in 1990 and continues to this day. Its objective has been the gradual, systematic and diversified evaluation of higher education and, at the same time, the establishment of a basis for its development, at least through the year 2020, with a view towards bringing Mexico into the society of knowledge.

\section{Evolution}

In the last third of the 20th century, Mexican higher educa- tion exhibited certain characteristics that were also visible in other countries (for an overview see Lorey, 1993). On the one hand, the student population was concentrated almost exclusively in the universities, and not in any other types of HEI such as technical institutes or teacher colleges. On the other hand, post World War II economic and demographic growth had brought with it increased levels of school attendance that over time tended to result in the accelerated growth of higher education. This gave rise to complaints of declining quality in the educational service as the overburdened teaching profession failed to keep up with the rising demands of students. Fears also began to arise as to whether job offers for university graduates would stay apace of graduation rates.

All of this sparked debate over the balance between quantity (the number of students enrolled) and quality of education, since, if an increase in student population without a matching change in the school experience led to a deterioration in quality (Honorable Cámara de Diputados, 1994), then this, in turn, could generate a distortion in the job market: well-educated professionals would become scarce while poorly prepared graduates would abound. In practice, the predominant focus of educational policy was on quantity, even if in official publications much was made on the importance of quality. Consequently, public policy after 1970 was characterized by numerous, though not always well-coordinated measures aimed chiefly at servicing a demand that the teaching profession, whose attention until then had been centered on two institutions (the National University and the National Polytechnic Institute), was unable to meet. It was lacking in infrastructure, membership and funding, among other things.

Attempts were made to deal with all of these problems at the same time, but with uneven results (Latapí, 1980). To begin with, educational policy tried giving structure and diversity to higher education by distributing students more evenly among the three branches: university, technological colleges and teacher 
colleges. This effort had limited success, with the university subsystem continuing its unchecked growth to the present day. Nevertheless, the foundation was laid for changes that continued to mature in subsequent years. The accomplishments were greater in the area of diversification; the options for areas of career majors opened up significantly, though less so, where enrollment by area of knowledge was involved. Growth remained out of control in this respect as well, in the sense that most students still signed up for a handful of traditional majors. Even nowadays, approximately $46 \%$ of undergraduate degree enrollment clusters around the Social and Administrative Sciences, home of some of the most traditional majors. This, too, is driven by an economic reality, namely, that this kind of major offers greater possibilities for placement in the job market.

New teacher-training programs were also initiated, as was systematic research on educational topics. Public financing of higher education, both nominally and in real terms, underwent a notable increase in the 1970s. But there were some marked failures in the creation and coordination of the system of higher education. The objective had been to organize the institutions of higher education into an unabridged whole possessing common goals, a plan which would allow for the effective use of supplies and the accomplishment of universal purposes. This, however, was blocked by the great heterogeneity and autonomy of the institutions of higher education. ${ }^{1}$

Moreover, in specifically political matters, public universities gained incentives for their role as the home of anti-government students and labor union protest movements, as provincial institutions once marginal to the conflict now joined the struggle. The unionizing of universities, which included both academics and administrators, also emerged in this period, creating a further focal point for conflict in higher education (Pulido, 1981). Nevertheless, two important differences prevailed in the relationship between the university's social movements and the government compared to the previous decade. First, the attitude taken by the federal government was that of non-involvement, as far as possible, in university conflicts. Secondly, and as a consequence, the watershed of university conflicts came either in confrontation with certain provincial governments or internally on the campi where students and labor unions, on one side, clashed with university leaders, on the other.

During this period the government undertook a broader array of reforms at every level of public administration. Where higher education was concerned, the goal was both to restore the ties between the government and the HEIs, and to set up a bureaucratic channel of communication that would serve as a transmission line for official policy. The National Association of Institutes of Higher Education, or ANUIES (Spanish acronym), began to gain prominence in this role. ANUIES is a non-governmental organization that joins the authorities of the chief HEIs, both public and private. It has an important lobbying function vis á vis political leaders, insofar as it negotiates for better conditions for the higher education system. By the same token, it serves as a bridge between the government and public HEIs in carrying out the directives of official educational policy (Medina Viedas, 2005).

The efforts undertaken yielded uneven results. Thereafter, policy would focus on propelling higher education towards a more consistent homogeneity (ANUIES, 1978). This effort

$\overline{{ }^{1} \text { Public universities in Mexico are autonomous by law and through the }}$ constitution. materialized as relations between the government and the public universities gradually stabilized, and as the economic picture brightened under the oil boom of 1977-1981, which allowed federal authorities to channel resources in exchange for certain agreements with educational institutions through ANUIES. These were agreements that revisited the idea of unifying higher education within a single system through generalized planning (regularly practiced by very few HEIs at the time) and the coordination of different education centers. Previously, similar proposals had failed to get off the ground for fear, among other reasons, of provoking new conflicts between the government and the universities.

Starting in 1978, several important measures were adopted through an agreement between the federal government, ANUIES and the HEIs: a National Plan for Higher Education was formulated; the National Law for the Coordination of Higher Education was approved; and finally, university autonomy was strengthened through the constitution (Villaseñor-García, 1988). These legal provisions were limited in their ef- fect. Although it seemed to fill a void, the National Act of Higher Education had little effect in practice. The National Plan for Higher Education had a marginally greater impact, but not exactly the kind sought. In order to implement it, the National Permanent Planning System for Higher Education (SINAPPES, Spanish acronym) had been launched, which aimed to generalize the practice of planning in all HEIs by setting up a graduated series of departments from national, regional and provincial levels down to the basic home campus level. At the national level there was the National Coordination for Planning in Higher Education (CONPES, Spanish acronym); at a regional level, the Regional Coordination for the Planning of Higher Education (CORPES, Spanish acronym), which grouped HEIs existing in geographical proximity with one another; for each province, the State Coordination for Planning in Higher Education (COEPES, Spanish acronym); and finally, Institutional Planning Units (UIPs, Spanish acronym) were created for all HEIs (CONPES, 1981).

These diverse organizational levels have had, to the present day, a highly irregular existence and performance. It was to be expected that an initiative of these dimensions would encounter problems in its execution, especially in the beginning phases. To be sure, there were advances as the HEIs accepted the need to plan their activities. Yet, communication among the different tiers of the planning system did not flow, as the architects of the policy would have wished. Given the conditions of extreme decentralization at the outset, it was difficult to bring about the fluid and efficient communication of guidelines from the center of the system of higher education to the periphery. As designed, the model was heavy and bureaucratic, and the critics maintained that the federal government had sought to oversee statistics (especially for enrollment, numbers of teachers and budget) rather than guarantee quality. Advances in the mere creation of new planning departments did not by themselves guarantee progress in the quality of education.

Incidentally, under this new system public financing grew stronger as a device of federal control over the growth of higher education and-given the scarcity of financial resources occasioned by the economic crisis that exploded in 1982 and lasted throughout the decade-it was to concentrate even greater power. But problems in implementing higher education planning on a national scale led to the adoption of a more precise and supple method, one aimed at verifying and measuring results: performance evaluations. These came into effect in 1989. 


\section{Current Policy}

The debate surrounding the quality of higher education and, consequently, the need to evaluate it, grew more heated as the failure of conventional planning, a model based on the simple idea of fitting the means to the ends, revealed its bureaucratic and impracticable nature. It is no accident that in Mexico's intellectual arena, the focus on public policy sciences, with its emphasis on sociological variables and the study of irrationality and contingency in public administration, had, at the same time, become fashionable (Aguilar-Villanueva, 1992). At an ideological level, the move towards evaluation coincided with the advent of the idea of equity, which was displacing equality, that is, stressing access to opportunity over the equal distribution of resources and, therefore, the justification of merit payment and rewarding productivity.

The new system for the evaluation of higher education instituted in Mexico was initially formulated with three orders of magnitude: self-evaluation by each center of education; peer evaluation of teaching programs and research projects by inter institutional peer committees; and the evaluation of the overall system by the office of the Secretary of Public Education (SEP, the equivalent of a ministry of education at the federal level). Currently, it is a manifestly more complex and developed system, one that encompasses the entirety of the educational system within different modalities (INEE, 2006). Theoretically, evaluation is part of the planning process, but with the relative atrophy of SINAPPES by the end of the eighties, it has taken on a life of its own. In its association with the allocation of funds, it places in the government's hands an agile instrument for some kind of recentralization of higher education without violating the legal autonomy of the universities. It is no longer a matter of a direct and thorough change of higher education, as was attempted in the early seventies and eighties, but rather of working towards certain precisely defined and manageable goals, which, cumulatively, would foster a chain reaction leading ultimately to more deeply rooted transformations.

The official policy is now being guided by a strategic planning perspective (ANUIES, 2000). Accordingly, it is supposed to be the case that, looking ahead to the 21st century, higher education policy must form part of an educational system that fulfills its strategic role for national development, thus attenuating acute social disparities by tapping into human capital, productivity and competitiveness. The foregoing offers a glimpse of a new scenario brought about by the globalization of which the country finds itself ever more a part of (especially since the signing of the North American Free Trade Agreement in 1994, involving the United States, Mexico and Canada), with its risk of polarization among, or within, countries, but also its opportunities. Despite its shortcomings, educational policy has helped to improve the status of the country's teachers, among whose ranks the number of $\mathrm{PhDs}$ has risen impressively over its previous, almost ludicrous, levels. With regard to accountability and quality control, there are now programs that yield consistent results, among them are the internal self-evaluation of the HEIs, the external evaluation, and other mechanisms.

Other important modifications have come about as a result of policies put into practice since the last century: the deconcentration of enrollment; the joint planning for the increase in educational supply within the federal states; the increase and diversification of programs in numerous branches of knowledge; the growth of post-graduate programs; greater participation by women in different areas of higher education, starting with enrollment itself. There is hope that the future will bring a greater push towards permanent education, the organization of higher education as a path to the society of knowledge (Ruiz Durán, 1997) and not merely as the pursuit of a terminal degree, the formation of innovators and entrepreneurs and the insertion of the HEIs within a new scenario of international competitiveness. It is foreseeable that the reinforcement of the participation of the leaders of higher education within the system of accountability through evaluations, accreditation and other mechanisms (including financial control) will continue. In general terms, cumulative changes in the system of higher education have produced and will continue to produce, in the course of the 21st century, innovations and restructurings that will be related to citizen formation in ways that go beyond the traditional vision centered on professions.

In consequence, long-term objectives have been established by stipulating strategic goals that should be met. According to these (ANUIES, 2000), HEIs should comprise a proper, interactive system in keeping up with its regional, national and international environment. Mexico should have a diversified, integrated and high-quality higher education system, broader in size and coverage, and should bring into its ranks at least $40 \%$ of the population between the ages of 20 and $24 .^{2}$ Furthermore, it should involve a wide array of HEIs, covering social and regional needs and ensuring quality in all of its institutions, while attaining an international level in its most developed ones. Each HEI would develop its own distinct pedagogy in relation to its needs using innovative models that would allow for quality and social relevance. In this regard, one determining factor, among others, would be the development of the so called "academic bodies," disciplinary or interdisciplinary active groups of dynamically prepared teachers and researchers who should be identified with their institution, as well as supported and increased in number so as to become the overall system's prime motivators and the guarantors of its quality (ANUIES, 2006). The HEIs would also focus their attention on the formation of students through well-integrated programs that would follow any student from before his or her entry into the system until after he or she has exited it, occupying itself with all aspects of academic development. This assumes an adequately diversified system, one capable of servicing different types of students. The institutions would fulfill their task of generating and applying knowledge of great quality and relevance for the country, along with the simultaneous development of the sciences. Mexico's higher education system would be capable of disseminating universal culture through proper ties with society and, in order to bring quality to the fulfillment of its function, it should have the necessary human resources at its disposal. This presupposes not only an increase in actual academic personnel, but also the resolution of problems in providing administrative and managerial personnel.

Along the same line, the HEIs should possess material and economic resources of sufficient quantity, quality, security and opportunity, both in terms of facilities and equipments as well as funding streams. Spending $2 \%$ of the GDP is the ideal for higher education; but currently this figure stands at about $1 \%$ of the GDP (OECD, 2011) considering both public and private spending. In any case, the aging population and the increase in

${ }^{2}$ The present number reaches $31 \%$ of the 19 to 23 year-olds, according to official information (Gobierno Federal, 2011). 
investment on education suggest that enrollment in higher education, and with it, investment at this level, will grow incrementally. Additionally, HEIs should feature organizational structure, standards and systems of governance that would favor their efficient functioning and cohere with their nature and mission. The legal framework would be consonant with the system's character while offering security and stability in the internal and external relations of its members. It would likewise ensure the provision of funds allocated by the state to public HEIs. The nationwide system of planning, evaluation, accreditation and quality assurance for higher education would be consolidated. The importance of the "academic bodies" as catalysts of the overall institution must be underscored in this regard.

In short, the fundamental values of this policy are: quality and innovation; the strengthening of academic quality; higher education's relevance to the country's needs; equity; a humanism that will inspire not merely a specialized or utilitarian education, but one that is guided by national and moral values; a commitment to building a better society; the responsible autonomy of the universities; and a fitting administrative and operational structure.

\section{Practice}

The implementation of the objectives of higher education policy appears within the framework of a system that is experiencing an important, albeit still inadequate, growth in student numbers. As a result, ensuring teaching quality has become a concern; but at the same time, in an emerging economy (as Mexico is according to the international opinion) the impulse towards research and innovation is also crucial. Both questions focus on HEIs. Scientific research in the country is done, above all, in public universities, a little less in state institutions and very little in private firms, dependent to a large degree on the importation of foreign technology (OECD, 2009). But not all Mexican HEIs carry out quality research with consistency and, in practice, are not expected to either, because social pressure as much as government policy points more towards the teaching profession. In practice, the higher education system is, above all, a teaching system and therefore the majority of teachers in higher education institutions are not researchers. In turn, high level researchers have a limited relationship with undergraduate students: they either give few classes at this level or do so within the framework of curricular content which is not always related to their research. Only at graduate and above all, doctorate level, is there a direct link between research and teaching. Among other causes, this is due to a characteristic of origin: historically, HEIs sprang up in different regions around the country to supply the demand for professionals, teachers and technicians, while research functions came later, or never in some institutions, or only in reduced scale (Varela-Petito, 2010).

Given the fact that enrollment poses specific problems, the official policy of recent decades has centered on stimulating an increase of students and, with some difficulties trying to ensure the quality of teaching. The pivotal point lies in academic demands, given that a minimal requirement model tends to predominate, particularly at an undergraduate level, making it difficult to stimulate the outstanding students and help the regular students overcome the obstacles on their path to knowledge. Although there are, naturally, variations depending on each teacher, this is a trait of the system and not of the individuals. In Mexican higher education, still marked by the traditional teaching model, teachers are recruited for their specialized knowledge but without having pedagogical training (because experience is laborious and requires the additional investment of time and teacher training), and in turn, the student with a basic educational background of routine, gap-ridden learning, is unprepared for active participation in the classroom (Guevara Niebla, 1997). Student performance evaluation methods are contingent on this (except when departmental or similar exams are implemented, which is not often in public HEIs) and must reconcile with the constraints identified. And the programs are not always up to date. It is not unusual to see reformulations of programs that, in the current institutional scheme, take years to complete. Curriculum design in accordance with university regulations, by collegiate bodies and special commissions, tend to cause this delay. During the process, rival academic groups may even argue at length over the content to be renewed. As a solution, some HEIs have adopted the practice of having academic authorities exclusively set the schematic characteristics of course curricula, leaving their periodic adjustment to ad-hoc academic committees selected for their knowledge and teaching commitment and which operate for a reasonable amount of time and with technical autonomy.

In this context, the generalization of the evaluation practices of researchers and teachers (Varela-Petito, 2011) puts pressure on academics not only through productivity requirements but also through the demand for diversification of tasks. Postgraduate studies, especially PhDs, which have been very motivated by the current policy of economic stimuli, point to this goal. As far as the government policy is concerned on higher education development, the key lies in the already cited academic bodies (Rubio Oca, 2006a). Innovation is of crucial importance here, as well as the incorporation of technology and its integration into the society of knowledge. On the question of financing, the importance of grants must be stressed, as they help restrict the tide of student desertion currently afflicting higher education, as well as other branches of the system (Rubio Oca, 2006b). ${ }^{3}$

\section{Interpretation}

In a developing country like Mexico, policy sets out to overcome the social obstacles to educational progress; the first of these is the socio-economic origin of the students, which the social orientation of policies and the allocation of resources seek to cushion (Poder Ejecutivo Federal, 2007). The immediate action must be to put public education within everyone's reach, guaranteed by the state and with the objective of passing from basic education up to the very highest levels of education over time. The educative institution is, to the student, not only an environment in which to learn a curriculum, but also to socialize by coming into contact with a diverse medium outside his or her family. The learning it offers is different from the one he or she receives at home and also broader than that produced strictly in the classroom.

Mexican higher education, therefore, has been changing since the end of the 20th century and no longer engages only with the training of university professionals or elite education groups. It has become a highly diversified system, one that

${ }^{3}$ Currently, from a total of around 3,000,000 higher education students, 400,000 receive scholarships (Gobierno Federal, 2011). 
tends to encompass ever more individuals, whether because the educative cycle extends as life expectancy is prolonged, or because the integration of knowledge into society requires a prolonged, continual and mass education, whose realization is also a legitimate requirement for the government. Training in public higher education is accessible for an increasingly greater number of people, even in countries like Mexico where such development was somewhat delayed. The expansion of the private sector, which has also happened in other Latin American countries, and which accounts for $30 \%$ of total higher education enrollment, is associated with this phenomenon: middleor high-income social groups, whether for reasons of academic quality, safety in installations, values or desire for exclusivity, feel the places they once occupied in public universities are now disturbed or threatened by the appearance of a number of students of a social type who did not frequent them before and seek to create their own spaces regulated by a price system. Nevertheless, the fundamental contradiction does not lie in public-private differentiation but in higher education seeking to respond to the circumstances of a developing society, correcting structural defects such as inequality, injustice or mismatching; and in doing so, finds itself having to deal with a group of very differentiated educational organizations, with a poorly coordinated performance logic. Given this complexity, the education system becomes an organizational and political problem in itself. Such is the outcome of this expansive phenomenon driven by social requirements, such as the student's accumulation of knowledge in order to penetrate the job market, but also, and this should be emphasized, by an internal logic of the academic institutions.

Educational authority, federal or at the state level, plays an important, but relative part in the process. Planning a design on a national scale and the allocation of resources gives it a significant power, but the impact is buffered by the de jure or de facto autonomy of the set of HEIs, propped up by reasons of legality or specialization of the service, and also for political reasons. Although the results produced by educational policy are not exactly as expected, the higher education system continues to embrace an ever-greater number of students, who graduate at an adult age largely without previous work experience, and in current circumstances without the assurance of finding a well-paid job in line with their professional training (OECD, 2008). Higher education operates under its own logic because its growth increasingly requires academics and other support workers, as well as supplies and investments, putting demands on the state budget and creating a double-edged political effect. On the one hand, the government seeks to control the use of resources by motivating its participation in education planning and placing conditions on the development of HEIs, and on the other hand, it receives social complaints and criticism from intellectuals and the press either for insufficient provision of resources, educational shortcomings or encroachments on academic spaces. The solution from the government's point of view has been to allow the parallel expansion of private HEIs, which relieve the public system of both budgetary demands and political pressure.

In turn, as far as the public sector of HEIs, the education process is increasingly permeated by evaluation mechanisms prompted by educational policy which range from the evaluation and certification of students by organisms outside the HEIs to the evaluation of the academics, institutions and administrative processes themselves, still without having a clear vision of the effects this will have in the classroom.

\section{Conclusion}

Presently, higher education in Mexico strives to be a combination of actions carried out both at the institutional and the systemic levels, wherein the objectives are spelled out under headings such as students, innovation, university-industry relations and scheduling. An open higher education system is sought, one based on scientific networks, which would bring within its scheme of relationships elements of civil society, the political system and employers. Progress in these characteristics would imply better communication among the HEIs and less isolation of academics within their home institutions. Focus would shift from organizational apparati to formal as well as informal efficient relationships.

Academic planning, even with the corrections introduced by experience and the refinement of theories and practices, seeks the homogenization of a mass service, which clashes with the peculiarities of the different organizational cultures of academics, officials, administrators, students and classroom groups. Educational policy prepares general guidelines for standardizetion purposes, but given the regionalization and heterogeneity of the institutions which comprise the higher education subsystem, reality demonstrates the survival of idiosyncrasies and the difficulty of obtaining unified results according to plan.

Despite these obstacles, the evaluation has been established through mechanisms that are also common in other countries (Bleiklie \& Henkel, 2010). Since 1988 the educational policy sought to give a new direction to higher education based on a closer relationship with the economy. This provoked tensions with academic groups that saw reforms-carried out with managerial criteria of accountability- as diluters of intellectual traditions. Nevertheless, the new policy, reliant essentially on evaluation mechanisms and merit payments, made its way at an individual level through the supply of economic stimuli additional to salaries, which in turn contributed to the relative weakening of power of the university unions. Some public universities also made structural transformations that led them to redesign the method of appointing their authorities, limiting the power that previously had been held by a broad range of institutional actors such as professors, students, and administrative staff (Doger Corte et al., 1998).

Following the same international patterns, the evaluation became systematically organized and based on quantitative rather than on qualitative criteria. Before the 1990s the predominant forms of recognition in the academic world were informal, based sometimes on the prestige earned by effort, but also on simple leadership capacities within the communities, not necessarily linked to the realization of important work. The current patterns have changed both aspects. Organized evaluation is governed by normative patterns and with fundamentally quantitative criteria: how much is produced within a determined range of products in a given amount of time. The result greatly depends on statistics. Moreover, evaluation and accreditation have extended, as was explained above, beyond personal instances, whether entire institutions or individually considered academic programs.

\section{REFERENCES}

Aguilar-Villanueva, L. (1992). El estudio de las políticas públicas. Me- 


\section{G. VARELA-PETITO}

xico, DF: Miguel Angel Porrúa.

ANUIES (2006). Consolidación y avance de la educación superior en México: Elementos de diagnóstico y propuestas. Mexico, DF: Asociación Nacional de Universidades e Institutos de Educación Superior.

ANUIES (2000). La educación superior en el siglo XXI: Líneas estratégicas de desarrollo. Mexico, DF: Asociación Nacional de Universidades e Institutos de Educación Superior.

ANUIES (1978). La planeación de la educación superior en México. Mexico, DF: Asociación Nacional de Universidades e Institutos de Educación Superior.

Bleiklie, I., \& Henkel, M. (Eds.) (2010). Governing knowledge: A study of continuity and change in higher education. Dordrecht, SH: Springer.

CONPES (1981). Plan nacional de educación superior: Lineamientos generales para el período 1981-1991. Mexico, DF: SEP-ANUIES.

Coombs, P. H. (1967). The world educational crisis: A systems analysis. Paris: International Institute for Educational Planning.

Doger Corte, J. et al. (1998). Transformación de las universidades públicas en los noventa. Mexico, DF: ANUIES.

Gobierno Federal (2011). Quinto informe de gobierno. Mexico, DF: Gobierno de los Estados Unidos Mexicanos.

Guevara Niebla, G. (1997). La catástrofe silenciosa. Mexico, DF: Fondo de Cultura Económica.

Honorable Cámara de Diputados (1994). Diagnóstico y prospectiva de la educación superior en México. Mexico, DF: H. Cámara de Diputados and Universidad Autónoma Metropolitana.

INEE (2006). Políticas y sistemas de evaluación educativa en México. Avances, logros y desafíos. Mexico, DF: Instituto Nacional para la Evaluación de la Educación.

Latapí, P. (1980). Análisis de un Sexenio de Educación en México. Mexico, DF: Fondo de Cultura Económica.
Lorey, D. E. (1993). The university system and economic development in Mexico since 1929. Palo Alto, CA: Stanford University Press.

Medina Viedas, J. (2005). La ANUIES y la educación superior en México 1950-2005. Mexico, DF: ANUIES.

OECD (2011). Education at a glance 2011. Paris: OECD.

OECD (2009). OECD Reviews of innovation policy: Mexico. Paris: OECD.

OECD (2008). OECD Reviews of tertiary education: Mexico. Paris: OECD.

Poder Ejecutivo Federal (2007). Plan nacional de desarrollo 2007-2012. Mexico, DF: Presidencia de la República.

Pulido, A. (1981). Cronología: 50 años de sindicalismo universitario. Mexico, DF: STUNAM.

Rubio Oca, J. (2006a). La mejora de la calidad de las universidades públicas en el período 2001-2006. Mexico, DF: Secretaría de Educación Pública.

Rubio Oca, J. (2006b). La política educativa y la educación superior en México. 1995-2006: Un balance. Mexico, DF: Fondo de Cultura Económica.

Ruiz Durán, C. (1997). El reto de la educación superior en la sociedad del conocimiento. Mexico, DF: ANUIES.

Varela-Petito, G. (2011). Evaluating public higher education in Mexico. Higher Education Management and Policy, 23, 59-78. doi:10.1787/hemp-23-5kg6mmx7sz9q

Varela-Petito, G. (2010). Facing the knowledge society: Mexico’s public universities. Higher Education Policy, 23, 436-449. doi:10.1057/hep.2010.15

Villaseñor-García, G. (1988). Estado y universidad, 1976-1982. Mexico, DF: Universidad Autónoma Metropolitana. 